\title{
Olympic ranking based on a zero sum gains DEA model
}

\author{
Marcos P. Estellita Lins a, Eliane G. Gomes ${ }^{\text {b,* }}$, João Carlos C.B. Soares de \\ Mello ${ }^{\mathrm{c}}$, Adelino José R. Soares de Mello ${ }^{\mathrm{d}}$ \\ ${ }^{a}$ Production Engineering Program, Federal University of Rio de Janeiro, Cidade Universitária, Centro de Tecnologia, Bloco F, \\ Sala F-105, 21945-970 Ilha do Fundão, Rio de Janeiro, RJ, Brazil \\ b Satellite Monitoring Research Center, Brazilian Agricultural Research Corporation (Embrapa), Av. Dr. Júlio Soares de Arruda, 803, \\ Parque São Quirino, 13088-300 Campinas, SP, Brazil \\ ${ }^{c}$ Production Engineering Department, Fluminense Federal University, Rua Passo da Pátria, 156, São Domingos, 24210-240 Niterói, RJ, \\ Brazil \\ ${ }^{\mathrm{d}}$ The MDF Geste and Diorama Industrial Groups, Praça da Alegria, 8 r/c, 1250-004 Lisbon, Portugal
}

\begin{abstract}
It is usual to rank the participant countries in the Olympic Games in accordance with the number of medals they have won. An alternative ranking is suggested in this paper. This ranking is based on each country's ability to win medals in relation to its available resources. This is an efficiency that can be measured with the help of data envelopment analysis (DEA) for which two models exist: the traditional DEA model, that takes into account variable returns to scale, and a DEA model based on the premise that the sum of the gains is zero (constant sum of outputs). It is the latter that is developed in this paper.
\end{abstract}

(c) 2002 Elsevier Science B.V. All rights reserved.

Keywords: Data envelopment analysis; Zero sum gains; Olympic ranking

\section{Introduction}

The Olympic Games were born in ancient Greece and were designed for individual contests. However, the cities from where the winners originated would grant them numerous prerogatives, clearly showing that the city felt it had won as well. The modern Games, initiated in 1896 by

${ }^{*}$ Corresponding author.

E-mail addresses: lins@pep.ufrj.br (M.P.E. Lins), eliane@cnpm.embrapa.br (E.G. Gomes), gmajcsm@vm.uff.br (J.C.C.B. Soares de Mello), ajrsoaresdemello@mail.telepac.pt (A.J.R. Soares de Mello).
Baron Coubertin, tried to keep the initial spirit of individual competition. That purpose clearly failed. Ever since the very first modern Games, it became usual to play the national anthem of the winner's country. During the Cold War the national character of the contest became ever more noticeable and developed into a true battle between East and West. Even before that, the Third Reich had tried to show the supremacy of the Arian race in the Games of 1936, although the results were quite different from those Hitler had bargained for.

In spite of the real competition between nations, the Olympic Committee has never published an official ranking that would allow a country to 
be classed as the overall Olympic Games winner. The media, however, did so in a way discussed below and which has become the quasi-official ranking.

Olympic rankings are traditionally published as a table in which countries are ranked in accordance with the number of gold, silver and bronze medals their athletes have won. This type of ranking is typical of the lexicographic multicriteria method (Barba-Romero and Pomerol, 1997), which, in this particular case, has the disadvantage to overvalue the gold medal. In other words, countries that win a high number of silver and bronze medals but none of gold are ranked below countries that have won a single gold medal. This method assumes that the decision-maker has the ability to rank criteria in accordance to their perceived importance. So the ranking depends on which criterion is thought to be the most important regardless of the other criteria. Should there be a tie, the ranking follows the second most important criterion and if a new tie obtains, it follows the third until the ranking is completed. In the case of the Olympic ranking, the first criterion is the number of gold metals, the second those of silver and, finally, those of bronze.

This paper proposes a different ranking based on data development analysis and analyses the results of Sidney 2000 Olympic Games. It considers the number of all types of medals won by each country as outputs and the population and GDP of that country as resources to win those medals. The decision making units (DMUs) are those countries that win at least one medal in Sidney 2000 Olympic Games. A new data envelopment analysis (DEA) model is required because the total number of medals to be won is constant. The classic DEA model is used as starting point for the development and use of the modified model that is henceforth called the zero sum gains DEA model (ZSG-DEA).

\section{Olympic efficiency analysis: Use of traditional data envelopment analysis}

The aim of DEA, proposed by Charnes et al. (1978), is to compare a certain number of DMUs that perform similar tasks but which use a different level of inputs to achieve different level of outputs. Besides identifying efficient DMUs, DEA models allow inefficiencies to be measured and diagnosed. It also determines a piece-wise linear production function that provides a benchmark for inefficient DMUs.

In this paper, we use variable returns to scale DEA model-DEA BCC-(Banker et al., 1984), because there is no evidence of any proportionality between inputs and outputs. An output-oriented model has been adopted because the obvious aim for every country is to win as many medals as possible.

As for the choice of inputs, it has been assumed that the greater the population of a country the better are the chances to produce good athletes and, therefore, to win medals. The existence of good athletes per se may be insufficient; the proper conditions for their training and improvement of their capacities have to be provided as well. The richer the country the easier it will be for these conditions to be met. Thus, inputs are a country's population and its wealth.

While country populations are easily obtainable data, their wealth can be measured in accordance with several criteria. However, only a couple of them allow adequate comparisons to be made. The best known and most usual is the country's total production excluding exports and imports that is called the gross domestic product (GDP). The comparison between the GDP of different countries provides a reasonably approximate measure of their relative levels of wealth. However, GDP as such presents some distortions, one of them being that the level of prices is different from country to country. To compensate for this deficiency, a fictitious exchange rate is used that takes into account the relative difference in prices and thus establishes the rate of exchange at purchasing power parity (PPP). Although GDP at PPP is available for many countries, the authors have had to estimate its value for some others.

In this paper, we have considered using either GDP or GDP per capita, but ultimately opted for GDP, given that the magnitude of 
governmental support to Olympic sports should be better explained by the former. We realised that a country with a large GDP per capita and a small population could have enough rich people but not big enough investments in sports. On the other hand, a country with a small GDP per capita but a large total GDP, could have more resources to invest in sports, although its people are poorer.

Another variable that could have been used as input is the country's investment in sports. This is a difficult figure to have reliable access to and, for that reason, was discarded.

Original DEA models (Cooper et al., 2000) allow each DMU to choose in complete freedom the weight for each output. This may mean that the efficiency score of some DMUs will depend on having valued the silver or bronze medals more highly than the gold one. To avoid this kind of distortion, a model with weight restrictions is used (Andersen and Petersen, 1993) that implies that the weight assigned to the output "number of gold medals" is higher than or equal to the one for the "number of silver medals". The same holds for silver and bronze medals.

Let it be recalled that in the traditional DEA models there is a number of reference units whose inputs and outputs define the efficiency frontier. The aim is to make the less efficient object unit at least as efficient as the others by increasing its output and, thus, join the frontier.

The BCC envelope model with weight restrictions as applied to the Olympic Games is here represented by the set of expressions (I). In this model, $\mathrm{DMU}_{0}$ is the object unit that is attempting to increase its output; $\mathrm{DMU}_{j}$ are the reference units used to establish the efficiency frontier for $\mathrm{DMU}_{0}$. The efficiency of $\mathrm{DMU}_{0}$ is $1 / h_{0}$; $x_{\mathrm{POP} j}$ and $x_{\mathrm{GDP} j}$ are the population and GDP PPP inputs for each $\mathrm{DMU}_{j} ; y_{\mathrm{G} j}, y_{\mathrm{S} j}$ and $y_{\mathrm{B} j}$ are the number of gold, silver and bronze medals outputs for each $\mathrm{DMU}_{j} ; \gamma_{1}$, and $\gamma_{2}$ are the decision variables that express the weight restrictions (Lins and Silva, 2001). As $\mathrm{DMU}_{0}$ becomes efficient it is projected on to the frontier. This is $\mathrm{DMU}_{0}$ 's target, and $\lambda_{j}$ is each efficient $\mathrm{DMU}_{j}$ 's individual share in the definition of the target for $\mathrm{DMU}_{0}$.

$$
\begin{array}{ll}
\max & h_{0} \\
\text { s.t. } & \sum_{j} \lambda_{j} x_{\mathrm{POP} j} \leqslant x_{\mathrm{POP} 0} \\
& \sum_{j} \lambda_{j} x_{\mathrm{GDP} j} \leqslant x_{\mathrm{GDP} 0} \\
& h_{0} y_{\mathrm{G} 0} \leqslant \sum_{j} \lambda_{j} y_{\mathrm{G} j}-\gamma_{1} \\
& h_{0} y_{\mathrm{S} 0} \leqslant \sum_{j} \lambda_{j} y_{\mathrm{S} j}+\gamma_{1}-\gamma_{2} \\
& h_{0} y_{\mathrm{B} 0} \leqslant \sum_{j} \lambda_{j} y_{\mathrm{B} j}+\gamma_{2} \\
& \sum_{j} \lambda_{j}=1 \\
& \lambda_{j}, \gamma_{1}, \gamma_{2} \geqslant 0
\end{array}
$$

Among the 80 countries that have won at least one medal, 7 result efficient in this model, i.e., they have won the number of medals compatible with their potentialities: Australia, Bahamas, Barbados, Cuba, United States, Macedonia and Russia. Of these, Barbados and Macedonia did not win gold medals and their inclusion among efficient countries is caused by a characteristic of the DEA model (DMUs with fewer resources are considered efficient regardless of their results).

The here above applied DEA model assumes that there is complete output independence, i.e., the output of any given DMU does not affect the output of the others. When outputs are ranks in contests, this independence does not exist: the higher the position of any given competitor the more he pushes down the positions of those below him. In the case of the Olympic Games, a country that has won more medals or obtained better medals automatically makes other DMUs not to win those medals, i.e., makes them lose output units.

To take this point in consideration, a new model is proposed. Its theoretical development is the object of the next section.

\section{Zero sum gains DEA model}

The ZSG-DEA assumes that the sum of outputs is constant. This is similar to a zero sum game in which whatever is won by a player is lost by one or more of the others. 
The model is represented in the general set of expressions (II), in which $\mathrm{DMU}_{0}$ is the object unit that is attempting to increase its output. Thus, $h_{\mathrm{R} 0}$ is the reciprocal of the $\mathrm{DMU}_{0}$ efficiency under ZSG-DEA; $x_{j}$ are the original inputs values; $y_{j}$ are the original outputs values; $y_{0}$ and $x_{0}$ are the output and input values for $\mathrm{DMU}_{0} ; y_{j}^{\prime}$ are the new outputs of the other DMUs resulting from the loss of outputs caused by $\mathrm{DMU}_{0}$ 's gains; $\lambda_{j}$ is the share defined in Section 2; $z$ represents how much $\mathrm{DMU}_{0}$ should gain to reach the efficient frontier; $\lambda_{j}, h_{\mathrm{R} 0}, y_{j}^{\prime}=f_{j}\left(h_{\mathrm{R} 0}\right)$ are the decision variables.

$$
\begin{array}{ll}
\max & h_{\mathrm{R} 0} \\
\text { s.t. } & \sum_{j} \lambda_{j} x_{j} \leqslant x_{0} \\
& h_{\mathrm{R} 0} y_{0} \leqslant \sum_{j} \lambda_{j} y_{j}^{\prime} \\
& \sum_{j} \lambda_{j}=1 \\
& \lambda_{j} \geqslant 0
\end{array}
$$

There are different solutions for this problem depending on the definitions of functions $y_{j}^{\prime}=$ $f_{j}\left(h_{\mathrm{R} 0}\right)$. One case in which the frontier does not change is one in which the object DMU wins units of lost output by DMUs that are not in the frontier. In other words, $y_{j}^{\prime}=y_{j}, \forall \mathrm{DMU}_{j} \in$ efficient frontier. However, this is a strategy that severely limits $\mathrm{DMU}_{0}$ 's ability to fulfil its target, i.e., to reach the frontier of efficiency.

Two other strategies to reach the target and their mathematical representation will be presented here below: a strategy that assumes equal reductions of output for all DMUs and a strategy in which the output reduction in each DMU is proportional to the DMU's very output. Algebraic representation of these two strategies applies to the general model without weight restrictions. The ZSG-DEA model with weight restrictions will be presented in Section 4.

\subsection{Equal output reduction strategy for all DMUs $j, j \neq 0$}

Fig. 1 shows a segment of two efficient frontiers. The upper line indicates the frontier of the traditional model; the lower line indicates the new fron-

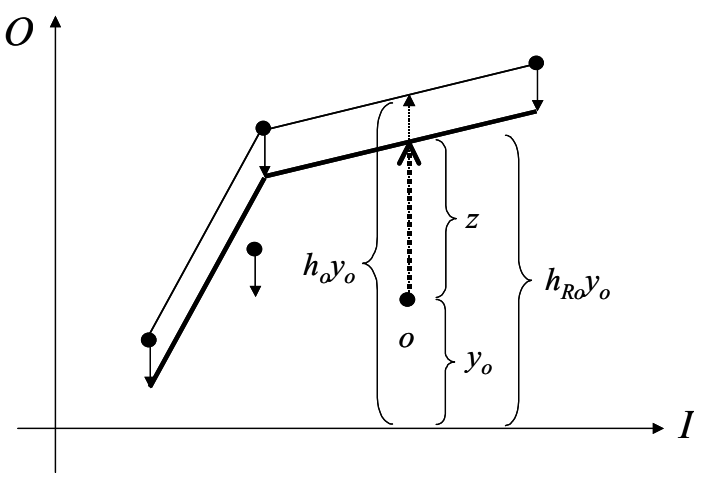

Fig. 1. Graphical representation of the equal output reduction strategy for all DMUs $j, j \neq 0$.

tier if all DMUs undergo an equal reduction of output with the exception of $\mathrm{DMU}_{0}$, which, to become efficient, wins the sum of the losses of the others.

As the distance to frontier in the ZSG-DEA model is shorter than the distance to the frontier in the traditional DEA model, the DMU,'s ZSGDEA efficiency is higher than the traditional one.

To represent this strategy we start with the general model set of expressions (II), in which the $\mathrm{DMU}_{0}$ 's output is $y_{0}$. The outputs of the other $(n-1)$ DMUs are $Y-y_{0}$, in which $Y$ is the sum of all available outputs for all DMUs.

Thus, $\mathrm{DMU}_{0}$ would need to win $z$ units of output and every other $\mathrm{DMU}_{j}, j \neq 0$, would lose $z /(n-1)$ output units. Therefore, $y_{j}^{\prime}=y_{j}-$ $(z / n-1)$.

Fig. 1 shows that the gain of $\mathrm{DMU}_{0}$ is $z=$ $h_{\mathrm{R}} y_{0}-y_{0}$. Substituting the values of $y_{j}^{\prime}$ and $z$ in (II), the model that represents the equal output reduction strategy is obtained (III).

$$
\begin{array}{ll}
\max & h_{\mathrm{R} 0} \\
\text { s.t. } & \sum_{j} \lambda_{j} x_{j} \leqslant x_{0} \\
& h_{\mathrm{R} 0} y_{0} \leqslant \sum_{j} \lambda_{j}\left(y_{j}-\frac{y_{0}\left(h_{\mathrm{R} 0}-1\right)}{n-1}\right) \\
& \sum_{j} \lambda_{j}=1 \\
& \lambda_{j} \geqslant 0
\end{array}
$$

The term $y_{0}\left(h_{\mathrm{R} 0}-1\right) / n-1$ represents the loss that each $\mathrm{DMU}_{j}, j \neq 0$, must have for $\mathrm{DMU}_{0}$ to win $z=y_{0}\left(h_{\mathrm{R} 0}-1\right)$ output units. 
This strategy has the following drawbacks:

1. It is a non-linear programming problem (the second constraint is a multiplication of the two decision variables $\lambda_{j}$ and $h_{\mathrm{R} 0}: h_{\mathrm{R} 0} y_{0} \leqslant$ $\left.\sum_{j} \lambda_{j}\left(y_{j}-\left(y_{0}\left(h_{\mathrm{R} 0}-1\right) / n-1\right)\right)\right)$.

2. This strategy might cause some DMUs to have a negative output. So, this strategy can only be used in the cases when $(z / n-1) \leqslant \min \left(y_{j}\right)$. Clearly, this is not the case of the Olympic Games as there are DMUs with low output such as, for instance, the efficient DMU Macedonia that won only a bronze medal.

To avoid this drawback, a new strategy that reduces the losses in proportion to the original output is proposed.

\subsection{Proportional output reduction strategy for all $D M U s j, j \neq 0$}

To fulfil this strategy, $\mathrm{DMU}_{0}$ needs to win $z$ output units and the losses of the other DMUs are proportional to their levels of output, i.e., the lower the level of output the lower the loss and vice-versa. The condition that the sum of the losses is equal to the gains of $\mathrm{DMU}_{0}$ is still in force (the sum of outputs is constant).

Fig. 2 represents the new frontier created by this strategy. The thin line indicates the frontier of the traditional model; the bold line indicates the new frontier if all DMUs undergo a proportional reduction of output with the exception of $\mathrm{DMU}_{0}$ which wins the sum of the losses of the others to achieve efficiency.

Fig. 3 shows what proportional reduction would mean in the case of three DMUs. DMUs $A$ and $B$ have a high level of output, respectively $a$ and $b$. Let $c$ be the level of output of DMU $C$. For DMU $C$ to become efficient, it must have an output gain of $\delta$ units, thus reaching the $(c+\delta)$ level. Consequently, DMUs $A$ and $B$ lose output units $\alpha$ and $\beta$, which are respectively proportional to the initial $a$ and $b$ levels, their output levels going down, consequently, to $(a-\alpha)$ and $(b-\beta)$.

From Fig. 3 and making losses proportional to output, comes $a / \alpha=b / \beta$. As gains must be equal to the sum of losses, we have $\alpha+\beta=\delta$. Algebraic ma-

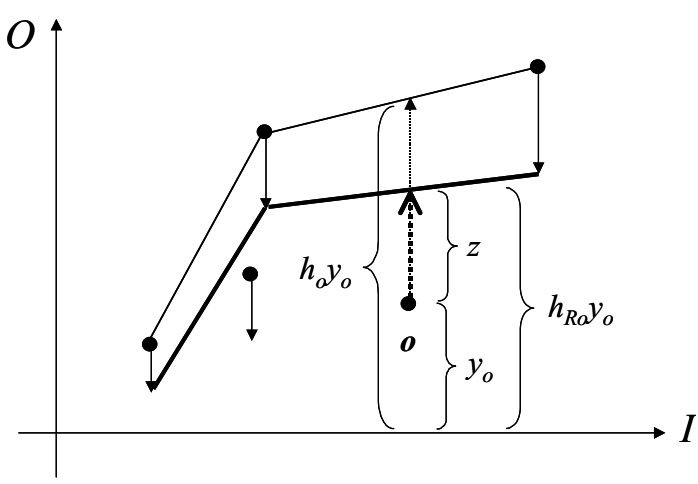

Fig. 2. Graphical representation of proportional output reduction strategy for all DMUs $j$.

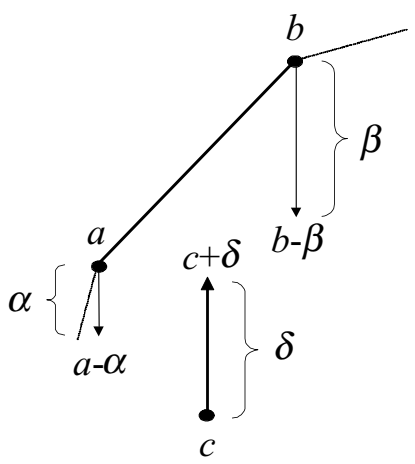

Fig. 3. Segment of an efficient frontier with the projection of DMU $C$, and proportional output reduction strategy for DMUs $A$ and $B$.

nipulation renders $\alpha=a \delta / a+b\left(\mathrm{DMU}_{A}\right.$ 's loss of

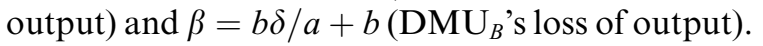

In general terms, the loss of output for any given $\mathrm{DMU}_{j}, j \neq 0$, becomes $y_{j} z / \sum_{j \neq 0} y_{j}$. As $z=$ $y_{0}\left(h_{\mathrm{R} 0}-1\right)$, the loss of output of $\mathrm{DMU}_{j}$ is $y_{j} y_{0}\left(h_{\mathrm{R} 0}-1\right) / \sum_{j \neq 0} y_{j}$.

Substituting this expression in the general model (II), model (IV) for the proportional output reduction strategy can be written.

$$
\begin{array}{ll}
\max & h_{\mathrm{R} 0} \\
\text { s.t. } & \sum_{j} \lambda_{j} x_{j} \leqslant x_{0} \\
& h_{\mathrm{R} 0} y_{0} \leqslant \sum_{j} \lambda_{j} y_{j}\left(1-\frac{y_{0}\left(h_{\mathrm{R} 0}-1\right)}{\sum_{j \neq 0} y_{j}}\right) \\
& \sum_{j} \lambda_{j}=1 \\
& \lambda_{j} \geqslant 0
\end{array}
$$


Term $1-\left(y_{0}\left(h_{\mathrm{R} 0}-1\right) / \sum_{j \neq 0} y_{j}\right)$ shall be called the reduction coefficient (RC).

Due to the constraint

$h_{\mathrm{R} 0} y_{0} \leqslant \sum_{j} \lambda_{j} y_{j}\left(1-\frac{y_{0}\left(h_{\mathrm{R} 0}-1\right)}{\sum_{j \neq 0} y_{j}}\right)$

this is still a non-linear programming problem. Besides, in real conditions there may be DMUs from which no proportional quantity of output can be extracted. A case in point in the last Olympic Games was Mozambique that won a gold medal but nothing else. In similar cases, strategies must be defined to withdraw an arbitrary number of units of output.

Non-linearity is not a difficulty in this case. Both in ZSG and traditional models the efficient frontier contains the same DMUs. On the other hand, for any DMU that does not belong to the $\mathrm{DMU}_{0}$ reference set, $\lambda_{j}=0$. So, the number of variables becomes rather small and, in some cases, the problem can be solved analytically with the use of differential calculus tools.

\section{The ZSG-DEA model applied to the Olympic Games}

\subsection{ZSG-DEA model with weight restrictions}

The previous paragraph makes it possible to establish a ZSG-DEA model that incorporates weight restrictions to the number of gold, silver and bronze medals that were won. The combination of models (I) and (IV) begets model (V) whose solution produces an Olympic ranking in which output reduction is proportional to its level.

Table 1

Results for some DMUs measured by the ZSG-DEA model with weight restrictions

\begin{tabular}{ll}
\hline DMU & Efficiency $(\%)$ \\
\hline Brazil & 14.62 \\
The Netherlands & 85.56 \\
Kenya & 24.51 \\
\hline
\end{tabular}

$$
\begin{array}{ll}
\max & h_{\mathrm{R} 0} \\
\text { s.t. } & \sum_{j} \lambda_{j} x_{\mathrm{POP} j} \leqslant x_{\mathrm{POP} 0} \\
& \sum_{j} \lambda_{j} x_{\mathrm{GDP} j} \leqslant x_{\mathrm{GDP} 0} \\
& h_{\mathrm{R} 0} y_{\mathrm{G} 0} \leqslant \sum_{j} \lambda_{j} y_{\mathrm{G} j}\left(1-\frac{y_{\mathrm{G} 0}\left(h_{\mathrm{R} 0}-1\right)}{\sum_{j \neq 0} y_{\mathrm{G} j}}\right)-\gamma_{1} \\
& h_{\mathrm{R} 0} y_{\mathrm{S} 0} \leqslant \sum_{j} \lambda_{j} y_{\mathrm{S} j}\left(1-\frac{y_{\mathrm{S} 0}\left(h_{\mathrm{R} 0}-1\right)}{\sum_{j \neq 0} y_{\mathrm{S} j}}\right)+\gamma_{1}-\gamma_{2} \\
& h_{\mathrm{R} 0} y_{\mathrm{B} 0} \leqslant \sum_{j} \lambda_{j} y_{\mathrm{B} j}\left(1-\frac{y_{\mathrm{B} 0}\left(h_{\mathrm{R} 0}-1\right)}{\sum_{j \neq 0} y_{\mathrm{B} j}}\right)+\gamma_{2} \\
& \sum_{j} \lambda_{j}=1 \\
& \lambda_{j}, \gamma_{1}, \gamma_{2} \geqslant 0
\end{array}
$$

Table 1 shows the efficiencies measured by this model for DMUs Brazil, The Netherlands and Kenya.

To obtain results in this model is very laborious owing to its non-linearity and large number of variables. The model would be greatly simplified if only one output existed. For the Olympic Games this means that the number of medals has to be condensed in one meaningful indicator only.

The theoretical considerations applicable to a single output ZSG-DEA model are shown herein below.

\subsection{Single output ZSG-DEA model solution}

For a single output ZSG-DEA proportional reduction strategy model the following theorem can be proven.

Theorem. The target for a DMU to reach the efficiency frontier in a ZSG-DEA proportional output reduction strategy model equals the same target in the traditional DEA BCC model multiplied by the reduction coefficient.

The theorem is represented by Eq. (VI), in which $j^{*}$ is the $\mathrm{DMU}_{0}$ reference set, $\lambda_{j}^{*}$ and $h_{0}^{*}$ are the optimal solutions of the traditional output oriented DEA BCC model. 


$$
\begin{aligned}
h_{\mathrm{R} 0} y_{0} & =\sum_{j^{*}} \lambda_{j}^{*} y_{j}\left(1-\frac{y_{0}\left(h_{\mathrm{R} 0}-1\right)}{\sum_{j \neq 0} y_{j}}\right) \\
& =h_{0}^{*} y_{0}\left(1-\frac{y_{0}\left(h_{\mathrm{R} 0}-1\right)}{\sum_{j \neq 0} y_{j}}\right)
\end{aligned}
$$

Proof. From the reduction/gain diagram shown in Fig. 4 and the similarities of triangles $A C d$ and $A B e$, shown in Fig. 5(a), as well as those of triangles, $A^{\prime} C^{\prime} d^{\prime}$ and $A^{\prime} B^{\prime} e^{\prime}$, shown in Fig. 5(b), the following relationships

$\frac{y_{B}-y_{A}}{y_{C}-y_{A}}=\frac{x_{B}-x_{A}}{x_{C}-x_{A}} \quad$ and $\quad \frac{y_{B}^{\prime}-y_{A}^{\prime}}{y_{C}^{\prime}-y_{A}^{\prime}}=\frac{x_{B}-x_{A}}{x_{C}-x_{A}}$

can be deducted. From these ratios it follows that

$\frac{y_{B}-y_{A}}{y_{C}-y_{A}}=\frac{y_{B}^{\prime}-y_{A}^{\prime}}{y_{C}^{\prime}-y_{A}^{\prime}}$

As $y_{B}^{\prime}=\mathrm{RC} y_{B}$ and $y_{A}^{\prime}=\mathrm{RC} y_{A}$, in which $\mathrm{RC}=$ reduction coefficient, $1 /\left(y_{C}-y_{A}\right)=\mathrm{RC} /\left(y_{C}^{\prime}-\mathrm{RC} y_{A}\right)$ is obtained. So, $\left(y_{C}-y_{A}\right) \mathrm{RC}=y_{C}^{\prime}-\mathrm{RC} y_{A}$, or rather, $y_{C}^{\prime}=\mathrm{RC} y_{C}$.

Although the proof has been carried out only for two dimensions, it is easy to generalise for a larger number of dimensions if orthogonal projections on the co-ordinated planes are used and similarity ratios are applied to the resulting triangles.

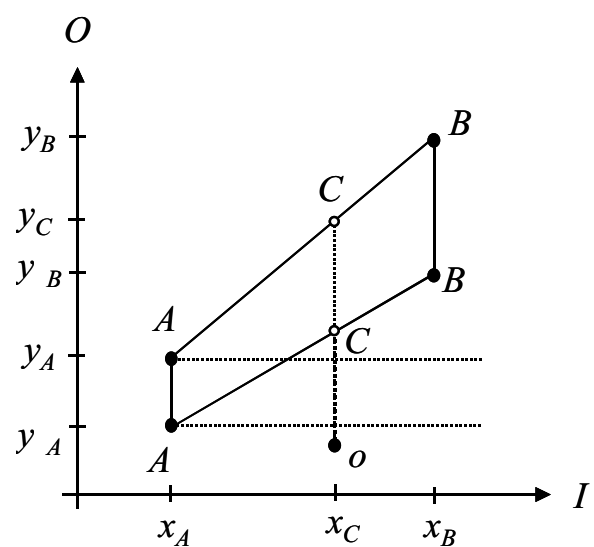

Fig. 4. Output reduction (DMU $\mathrm{DM}_{0}$ references DMUs $A$ and $B$ ) and output gain $\left(\mathrm{DMU}_{0}\right)$ for the proportional output reduction strategy.

Corollary. In a ZSG-DEA model in which a proportional output reduction strategy has been adopted, the value of the DMUs $j$ contribution $\left(\lambda_{j}\right)$, $j \neq 0$, equals its value in the traditional DEA model.

Proof. Consider the $\mathrm{DMU}_{0}$ (output $=y_{0}$ ) reference set which comprehends $p$ DMUs, with $y_{1}, y_{2}, \ldots, y_{p}$ outputs. $\mathrm{DMU}_{0}$ 's target is $h_{0} y_{0}=\lambda_{1} y_{1}+\lambda_{2} y_{2}+$ $\cdots+\lambda_{p} y_{p}$. Multiplying the equation by the reduction coefficient $\mathrm{RC}, \mathrm{RC} h_{0} y_{0}=\mathrm{RC} \lambda_{1} y_{1}+\mathrm{RC} \lambda_{2} y_{2}+$ $\cdots+\mathrm{RC} \lambda_{p} y_{p}$. From the preceding theorem $h_{\mathrm{R} 0} y_{0}=$ $\lambda_{1} y_{1}^{\prime}+\lambda_{2} y_{2}^{\prime}+\cdots+\lambda_{p} y_{p}^{\prime}$, and the corollary is proved.

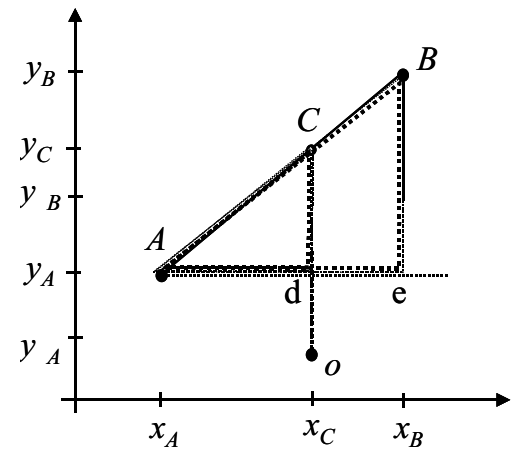

(a)

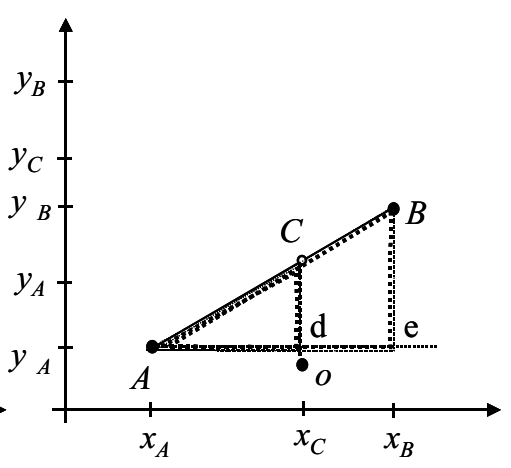

(b)

Fig. 5. Triangle similarity ratios for the proportional output reduction strategy. 


\subsection{Single output model used for Olympic rankings}

It has already been mentioned that the aggregation of the outputs "number of medals" into a single indicator is required. This aggregation of criteria defines the American Multicriteria School (Keeney and Raiffa, 1976) and is easily obtainable by means of a weighted sum in which the weights are the measure of the importance of each type of medal.

In Gomes et al. (2001), the weights were obtained from the expression of the decision-makers' preferences. This is very arbitrary and, so, preference was given to use the very DEA model to obtain the weights. The DEA BCC model with weight restrictions (Section 2) was used. The average of the weights that each DMU assigned to each type of medal was calculated from this model. To standardise procedures each weight was divided by the sum of weights the DMU assigned to each type of medal.

This approach has the advantage of being objective and, thus, it does not depend on experts' opinions. However, it does have the possible disadvantage of efficient DMUs not having a single set of optimal weights (Rosen et al., 1998; Soares de Mello et al., 2001). This is not a serious disadvantage in this case as the number of efficient DMUs is small and, so, it has little influence in the calculation of the average value. This technique allows the three-output model to be replaced by a single output model in which the aggregate output is obtained from Eq. (VII).

single output $=0.5814$ gold +0.2437 silver

$$
+0.1749 \text { bronze }
$$

The use of this output prevents each DMU from optimising its own weights. Despite this drawback, it simplifies the problem greatly. The fact that the frontier it determines is the same as found by model (I) further vindicates its use.

The use of the aggregate output, of the theorem and its corollary make it possible for efficiency to be determined from the classical DEA model and the resolution of Eq. (VI) when the sum of gains is zero.

The final Olympic ranking obtained from the single output ZSG-DEA model is shown in Ap- pendix A. It should be emphasised that the calculation of these results requires the previous calculation of the corresponding classical single output DEA BCC model to determine reference DMUs and their shares $(\lambda)$ or efficiencies $1 / h$.

The results show that a number of countries are tied at $100 \%$ efficiency. This is a common characteristic of the majority of DEA models, in particular of the DEA BCC model. ZSG-DEA, as a particular case of the DEA BCC model, suffers from the same drawback. The literature provides methods to overcome this difficulty (Adler et al., 2002). Mention can be made of cross-evaluation (Sexton et al., 1986; Doyle and Green, 1994), super efficiency (Andersen and Petersen, 1993) and benchmarking (Charnes et al., 1985), among others. The latter states that the more an efficient DMU is chosen as a target by the inefficient units, the better it ranks. This means that those inefficient DMUs have similar properties to the efficient one. Results from this approach can be seen in Table 2 .

Another property or DEA BCC model incorporated to the ZSG-DEA is that those DMUs with the smallest input value and/or the biggest output value are always efficient (Ali, 1994). In our case study, these DMUs are Barbados, Macedonia (smallest inputs) and United States (biggest output). In Table 2 it can be seen, indeed, that these DMUs belong to the peer groups of a small number of inefficient DMUs.

It should also be pointed out that efficiencies obtained from the multiple output ZSG-DEA models with weight restrictions have lower values than those obtained from the single output model.

Table 2

Ranking for the efficient countries based on the benchmarking method

\begin{tabular}{ll}
\hline $\begin{array}{l}\text { Efficient } \\
\text { DMU }\end{array}$ & $\begin{array}{l}\text { Number of times the efficient DMU appear } \\
\text { in the peer groups of the inefficient ones }\end{array}$ \\
\hline Australia & 55 \\
Cuba & 50 \\
Russia & 35 \\
Bahamas & 34 \\
Macedonia & 5 \\
United States & 4 \\
Barbados & 0 \\
\hline
\end{tabular}




\section{Conclusions}

Olympic efficiency as analysed by DEA models has been shown to be a useful tool to check whether each country has been obtaining results that are compatible with its potentialities. It further allows planning for realistic targets for future Olympic Games. However, traditional models do not take into consideration the limited number of medals to be won and, thus, some refinements are required. The ZSG-DEA model, weight constrained or otherwise, and the proposed strategies are the first step to obtain more accurate results.

The ZSG-DEA model with weight restrictions is not at present as much developed as the single aggregate output model. For this reason the latter has been chosen to establish the final ranking.

The following are only some of the future developments that can be envisaged for ZSGDEA:

- Strategies for co-operation and competition among inefficient DMUs;
- Taking into account that the quantity of medals is a integer leading to a non-linear and integer programming problem;

- To determine a strategy that, besides maximising $h_{\mathrm{R} 0}$, will also minimise $z$. This means determining the most efficient strategy that can be obtained from the adequate choice of the $f_{j}\left(h_{\mathrm{R} 0}\right)$. In such a case maximisation will require decision functions instead of decision variables and that will require the use of a dynamic programming problem. This strategy leads to a DEA model conceptually different from the existing ones, since the movement of an inefficient DMU towards the frontier will affect its shape.

\section{Acknowledgement}

We acknowledge the financial support of CNPq (Brazilian Ministry of Science and Technology).

\section{Appendix A}

Proposed ranking for winning medal countries in Sidney 2000 Olympic Games

\begin{tabular}{lrrrl}
\hline Country & Gold & Silver & Bronze & Eff $_{\text {ZSG-DEA }}-$ single output $(\%)$ \\
\hline Australia & 16 & 25 & 17 & 100.00 \\
Cuba & 11 & 11 & 7 & 100.00 \\
Russia & 32 & 28 & 28 & 100.00 \\
Bahamas & 1 & 1 & 0 & 100.00 \\
Macedonia & 0 & 0 & 1 & 100.00 \\
United States & 39 & 25 & 33 & 100.00 \\
Barbados & 0 & 0 & 1 & 100.00 \\
Romania & 0 & 4 & 3 & 76.20 \\
Norway & 11 & 6 & 9 & 74.59 \\
China & 4 & 3 & 3 & 73.05 \\
Germany & 28 & 16 & 15 & 71.05 \\
Hungary & 14 & 17 & 26 & 68.56 \\
The Netherlands & 8 & 6 & 3 & 63.93 \\
France & 12 & 9 & 4 & 60.14 \\
Bulgaria & 13 & 14 & 11 & 59.55 \\
Yugoslavia & 5 & 6 & 2 & 58.85 \\
Italy & 1 & 1 & 1 & 55.39 \\
Estonia & 13 & 8 & 13 & 52.10 \\
Slovenia & 1 & 0 & 2 & 48.61 \\
United Kingdom & 2 & 0 & 0 & 47.34 \\
Belarus & 11 & 10 & 7 & 45.50
\end{tabular}




\begin{tabular}{|c|c|c|c|c|}
\hline Country & Gold & Silver & Bronze & Eff $_{\text {ZSG-DEA }}-$ single output $(\%)$ \\
\hline Sweden & 3 & 3 & 11 & 45.12 \\
\hline Jamaica & 4 & 5 & 3 & 44.65 \\
\hline Lithuania & 2 & 0 & 3 & 44.31 \\
\hline South Korea & 8 & 9 & 11 & 43.62 \\
\hline Greece & 4 & 6 & 3 & 42.09 \\
\hline Ukraine & 3 & 10 & 10 & 39.63 \\
\hline Denmark & 2 & 3 & 1 & 36.74 \\
\hline Latvia & 1 & 1 & 1 & 36.13 \\
\hline Poland & 6 & 5 & 3 & 32.38 \\
\hline Switzerland & 1 & 6 & 2 & 31.84 \\
\hline Moldova & 0 & 1 & 1 & 30.51 \\
\hline Ethiopia & 4 & 1 & 3 & 30.12 \\
\hline Finland & 2 & 1 & 1 & 29.12 \\
\hline Slovakia & 1 & 3 & 1 & 27.61 \\
\hline New Zealand & 1 & 0 & 3 & 26.86 \\
\hline Czech Republic & 2 & 3 & 3 & 24.65 \\
\hline Trinidad \& Tobago & 0 & 1 & 1 & 24.55 \\
\hline Kazakhstan & 3 & 4 & 0 & 23.76 \\
\hline Kenya & 2 & 3 & 2 & 22.16 \\
\hline Iceland & 3 & 3 & 8 & 21.24 \\
\hline Georgia & 0 & 0 & 6 & 21.00 \\
\hline Canada & 0 & 0 & 1 & 20.91 \\
\hline Azerbaijan & 2 & 0 & 1 & 18.73 \\
\hline Spain & 2 & 1 & 0 & 17.39 \\
\hline Austria & 1 & 0 & 1 & 17.07 \\
\hline Croatia & 3 & 3 & 5 & 16.76 \\
\hline Qatar & 0 & 0 & 1 & 15.70 \\
\hline Kyrgyzstan & 0 & 0 & 1 & 11.53 \\
\hline Cameroon & 1 & 0 & 0 & 10.82 \\
\hline Algeria & 1 & 1 & 3 & 10.44 \\
\hline Mozambique & 0 & 2 & 3 & 10.18 \\
\hline Iran & 3 & 0 & 1 & 10.11 \\
\hline Belgium & 1 & 0 & 0 & 10.05 \\
\hline Uzbekistan & 1 & 1 & 2 & 9.99 \\
\hline Turkey & 0 & 6 & 6 & 9.49 \\
\hline Costa Rica & 0 & 0 & 2 & 9.12 \\
\hline Brazil & 3 & 0 & 1 & 8.97 \\
\hline Morocco & 0 & 0 & 1 & 8.39 \\
\hline Kuwait & 0 & 1 & 4 & 8.04 \\
\hline North Korea & 1 & 2 & 3 & 7.24 \\
\hline Uruguay & 0 & 1 & 3 & 6.91 \\
\hline Mexico & 0 & 1 & 0 & 6.77 \\
\hline South Africa & 1 & 3 & 2 & 6.03 \\
\hline Nigeria & 0 & 1 & 0 & 6.03 \\
\hline Ireland & 5 & 8 & 5 & 6.02 \\
\hline Indonesia & 0 & 3 & 0 & 5.99 \\
\hline
\end{tabular}




\begin{tabular}{lcccc}
\hline Country & Gold & Silver & Bronze & Eff $_{\text {ZSG-DEA }}-$ single output $(\%)$ \\
\hline Japan & 0 & 2 & 3 & 5.76 \\
Taiwan & 0 & 2 & 2 & 5.34 \\
Armenia & 0 & 0 & 1 & 4.74 \\
Argentina & 0 & 1 & 4 & 4.73 \\
Thailand & 1 & 0 & 2 & 4.64 \\
Portugal & 1 & 0 & 0 & 3.65 \\
Colombia & 0 & 0 & 2 & 3.58 \\
Saudi Arabia & 0 & 0 & 1 & 2.93 \\
Israel & 0 & 1 & 1 & 2.87 \\
Vietnam & 0 & 0 & 1 & 2.29 \\
Sri Lanka & 0 & 1 & 0 & 1.75 \\
Chile & 0 & 0 & 1 & 1.30 \\
India & 0 & 0 & 1 & 0.62 \\
\hline
\end{tabular}

\section{References}

Adler, N., Friedman, L., Sinuany-Stern, Z., 2002. Review of ranking methods in data envelopment analysis context. European Journal of Operational Research 140 (2), 249265.

Ali, A.I., 1994. Computational aspects of DEA. In: Charnes, A., Cooper, W.W., Lewin, A., Seiford, L.M. (Eds.), Data Envelopment Analysis: Theory, Methodology and Applications. Kluwer Academic Publishers, Boston, pp. 63-88.

Andersen, P., Petersen, N.C., 1993. A procedure for ranking efficient units in data envelopment analysis. Management Science 39 (10), 1261-1264.

Banker, R.D., Charnes, A., Cooper, W.W., 1984. Some models for estimating technical scale inefficiencies in data envelopment analysis. Management Science 30 (9), 1078-1092.

Barba-Romero, S., Pomerol, J.C, 1997. Decisiones Multicriterio: Fundamentos Teóricos y Utilización Práctica, Colección de Economía, Universidad de Alcalá, Spain.

Charnes, A., Clark, C.T., Cooper, W.W., Golany, B., 1985. A developmental study of data envelopment analysis in measuring the efficiency of maintenance units in the US air forces. Annals of Operations Research 2, 95-112.

Charnes, A., Cooper, W.W., Rhodes, E., 1978. Measuring the efficiency of decision-making units. European Journal of Operational Research 2, 429-444.

Cooper, W.W., Seiford, L.M., Tone, K., 2000. Data Envelopment Analysis: A Comprehensive Text with Models, Applications, References and DEA-Solver Software. Kluwer Academic Publishers, US.
Doyle, J.R., Green, R., 1994. Efficiency and cross-efficiency in data envelopment analysis: derivatives, meanings and uses. Journal of the Operational Research Society 45 (5), 567578.

Gomes, E.G., Soares de Mello, J.C.S., Lins, M.P.E., 2001. Uso de Análise Envoltória de Dados e Auxílio Multicritério à Decisão na análise dos resultados das Olimpíadas 2000, Proceedings of the VII International Conference on Industrial Engineering and Operations Management, Brazil, October.

Keeney, R.L., Raiffa, H., 1976. Decisions With Multiple Objectives: Preferences and Value Tradeoffs. John Wiley, New York, US.

Lins, M.P.E., Silva, A.C.M., 2001. Evitando a inviabilidade em modelos DEA com restrições aos pesos, Technical Report EP03/01-PO, Production Engineering Program-UFRJ, Rio de Janeiro, Brazil.

Rosen, D., Schaffnit, C., Paradi, J.C., 1998. Marginal rates and two dimensional level curves in DEA. Journal of Productivity Analysis 9 (3), 205-232.

Sexton, T.R., Silkman, R.H., Hogan, A.J., 1986. Data envelopment analysis: Critique and extensions. In: Silkman, R.H. (Ed.), Measuring Efficiency: An Assessment of Data Envelopment Analysis. Jossey-Bass, San Francisco, CA, pp. 73105.

Soares de Mello, J.C.C.B., Lins, M.P.E., Gomes, E.G., 2001. Estimativa de planos tangentes à fronteira DEA em DMUs extremo-eficientes, Proceedings of XXXIII Simpósio Brasileiro de Pesquisa Operacional, November, Brazil. 